\title{
Application of Pulsed Laser-TIG Hybrid Heat Source in Root Welding of Thick Plate Titanium Alloys
}

\author{
Jipeng Shi, Yanbin Zhou and Liming Liu * \\ Key Laboratory of Liaoning Advanced Welding and Joining Technology, School of Materials Science and \\ Engineering, Dalian University of Technology, Dalian 116024, China; shijp@mail.dlut.edu.cn (J.S.); \\ yanbinocean@mail.dlut.edu.cn (Y.Z.) \\ * Correspondence: liulm@dlut.edu.cn; Tel./Fax: +86-0411-8470-7817
}

Academic Editor: Stanislaw M. Dubiel

Received: 17 March 2017; Accepted: 26 April 2017; Published: 18 May 2017

\begin{abstract}
Laser-TIG (tungsten inert gas) hybrid welding process is applied to produce stable back beads in the first layer during one-side multilayer welding. To explain why stable back beads can be formed, a comparison is conducted between single TIG and laser-TIG hybrid welding. Results indicate that during laser action the arc column is enhanced and deflected to the keyhole, which changes the spatial distribution of plasma by strong attraction. The keyhole plasma possesses extreme electric conductivity. After laser action, the enhanced arc is restituted, the low energy density arc acts on the molten pool, and the bottom of the molten pool is solidified to prevent its collapse. The heat and force are redistributed over the top of molten pool under the alternative action of the enhanced arc and original arc. In this case the thermal distribution and mechanical situation in the molten pool must be more balanced and reasonable, and the back bead appearance is continuous, stable and uniform. This process gives high quality and efficient root welding of the thick plate.
\end{abstract}

Keywords: laser-TIG hybrid welding; root welding; deflected arc; alternative action

\section{Introduction}

Titanium alloys, which have already been considered as a kind of key developing structural materials with great strategic significance by a number of the world's dominant military powers, have been used in substitution aluminum alloys and steels in the aerospace, ship and chemical industries, etc., because they possess many good characteristics such as high strength to weight ratio, corrosion resistance and excellent weld-ability [1,2]. In recent years, due to the need for nation space science development, remarkable advances have been made in large-tonnage launch vehicles, spaceports and other equipment, and we have come a long way in production capacity and technology level of titanium alloys. The demand for titanium alloys with complex structural components with large volume and thickness is constantly increasing [3,4]. The advanced welding technology, which is considered as the common technique in components manufacturing, is one of the most attractive problems in the joining field of titanium alloys [5]. As we all know, multilayer multi-channel welding is a commonly used technology in conventional jointing of a thick mild plate. A stable formation of continuous weld in the first layer during the welding process is important to achieve welded joints with high quality and productivity [6]. Recently, several different welding methods have been developed to jointing titanium alloy. However, each of these methods has its own significant imperfection. Arc welding, which is the earliest method developed for titanium welding, has a low productivity. The electron beam welding has a limitation on the overall dimensions of the weld workpieces due to there the necessity of making a vacuum in the working chamber [7]. Laser welding, which is considered as a high-efficiency method, is the most promising jointing method for thick plates [8]. Campanelli S.L. et al. reported that a satisfactory titanium alloy joint can be achieved at high welding 
speed by $1.2 \mathrm{KW}$ laser welding process [9]. However, the laser welding process requires greater precision in the positioning of the pieces to be jointed. Thus, the researchers are stimulated to look for another welding process that has the ability to penetrate deeper into the workpiece and consequently reduce total heat input.

Laser-arc hybrid heat source, which possesses many new and unique merits, such as improved manufacturing stability, efficiency, quality and reduced energy consumption, is a mixed high energy density laser with an arc of good gap tolerance forming an efficient welding method [10-12]. The addition of a laser beam can improve the arc stabilities, whereas the arc can also play an efficient role in melting welding [13]. Thus, when the laser-arc hybrid welding was introduced, it attracted much attention from researchers in titanium alloy manufacturing. Truichin G. suggested that the technology of $5 \mathrm{KW}$ laser-TIG welding with filler wire of titanium alloys with a thickness of $5 \mathrm{~mm}$ has been developed [14]. By studying the $1.5 \mathrm{KW}$ laser-TIG hybrid welding process of thick plate, Zhang reported that a satisfactory weld can be obtained and the tension of the weld is higher than that of the TA15 alloy [15]. By carrying out 2.15 KW laser-MIG on titanium, M. Brandizzi et al. indicated that the weld appearance is sensitive to changes in the gap [11]. Liu, et al. published a paper in 2008, in which titanium alloy with $2.0 \mathrm{~mm}$ was joined successfully by pulsed laser-TIG hybrid welding [16]. However, most of the literature is focused on the larger energy laser or thin plate welding process; for root welding of thick plate titanium alloy, the literature is extremely limited [17].

In this study, root welding experiments were carried out on thick plate titanium alloys, and an experimental system was developed to implement the laser-TIG hybrid welding process. The authors investigated the regulatory effect of the pulsed laser on the thermal distribution and mechanical situation in the molten pool. The vision system was employed to observe the weld arc behaviors during the welding process. Another vision system was employed to observe the molten pool during the welding process. The spectrograph was employed to acquire the plasma spectra. The reason why stable back beads are formed by the hybrid welding process was explained.

\section{Experimental Procedures}

\subsection{Equipment Setup}

The experiments were performed at room temperature and atmospheric pressure. The heat source, which is similar to our previous report [18], was the combination of a pulsed Nd: YAG laser beam and a lateral-axial arc produced by a tungsten inert gas (TIG) welding machine, as schematically shown in Figure 1. The laser, with the wavelength of $1.064 \mu \mathrm{m}$, was focused by a lens with a focal distance of $120 \mathrm{~mm}$ into a spot measuring about $0.6 \mathrm{~mm}$. The average output power of the laser beam was within 0 to $1000 \mathrm{~W}$ by controlling the pulse energy, pulse duration and pulse frequency. In the hybrid welding process, the arc operated continuously while the laser operated in the form of pulses as shown in Figure 2. The workpiece was placed perpendicular to the laser beam. The angle of the tungsten electrode axis to the target was kept $45^{\circ}$. In addition, titanium alloy is identified as a highly reactive material at ambient gases, especially at high temperature. For this reason, during welding, a trailing and back shielding gas was used to protect the both sides of the molten pool from oxidation.

The SP-2556 spectrograph (Princeton Instruments, Princeton, NJ, USA) with $500 \mathrm{~mm}$ focus was used to acquire the plasma spectra. The fiber head was fixed to an X-Y controlled device, as shown in Figure 1, which acquires the accuracy of $0.01 \mathrm{~mm}$. Meanwhile, according to the welding plasma spectrum and NIST (National Institute of Standards and Technology, Gaithersburg, MD, USA) database, two narrow-band optical filters were employed to observe the distribution of Ti and Ar atoms in the plasma, as shown in Figure 3a. As shown in Figure 3a, the spectrum of the hybrid welding arc plasma with the wavelength from 200 to $1000 \mathrm{~nm}$ is acquired. It also can be seen that the arc plasma is mainly composed of $\mathrm{Ti}$ atoms, $\mathrm{Ar}$ atoms, $\mathrm{Ti}^{+}$ions and $\mathrm{Ar}^{+}$ions. In this research, three lines of $\mathrm{Ti}$ atoms (Ti I $439.39 \mathrm{~nm}$, Ti I $441.73 \mathrm{~nm}$ and Ti I $521.04 \mathrm{~nm}$ ) are selected to characterize the arc plasma in welding. In order to further study the plasma behavior, plasma spectrum at different locations in the 
vertical plane was acquired and analyzed, as shown in Figure $3 b$. In this process, the adjustment of the fiber head distance is $2 \mathrm{~mm}$ each time along the $Y$ axis from $0 \mathrm{~mm}$ to $4 \mathrm{~mm}$ and $1 \mathrm{~mm}$ each time along the $X$ axis from $0 \mathrm{~mm}$ to $7 \mathrm{~mm}$ in the coordinate plane, where position $(0,0)$ was the intersection of the base metal surface and the axis of laser beam and position $(0,4)$ is the position of the tungsten electrode tip. The electron temperature of every position was calculated and the calculated results were fitted by MATLAB (R2014a, Mathworks, Natick, MA, USA).

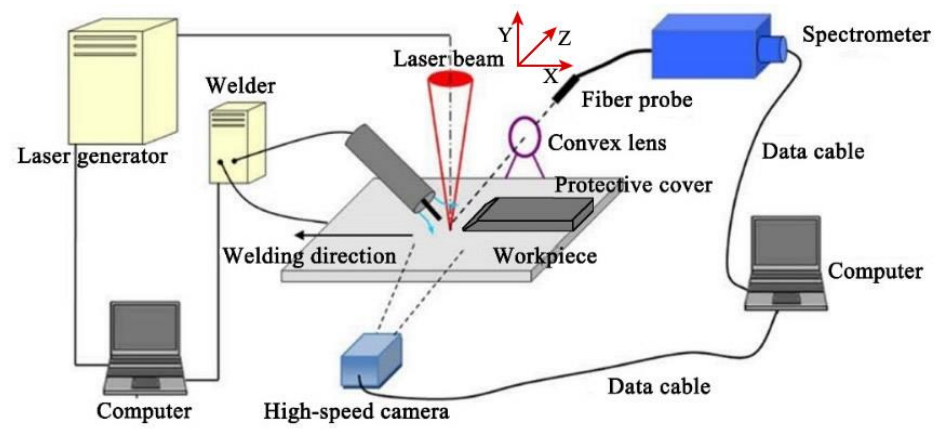

Figure 1. Sketch of experimental device.

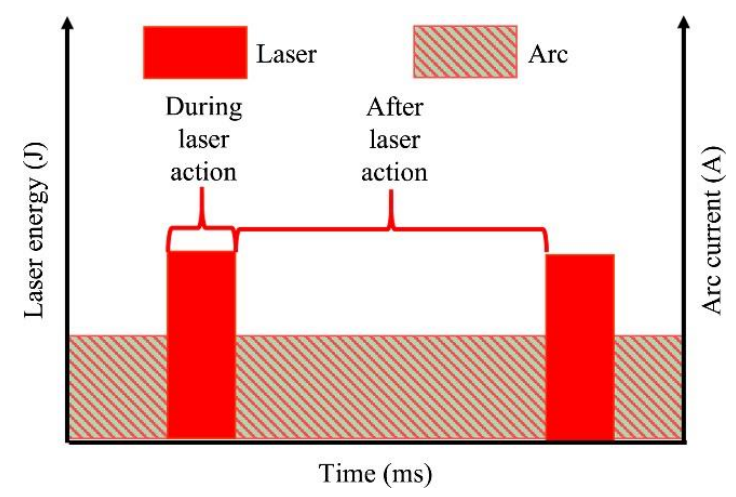

Figure 2. Schematic diagram of laser and arc action period.
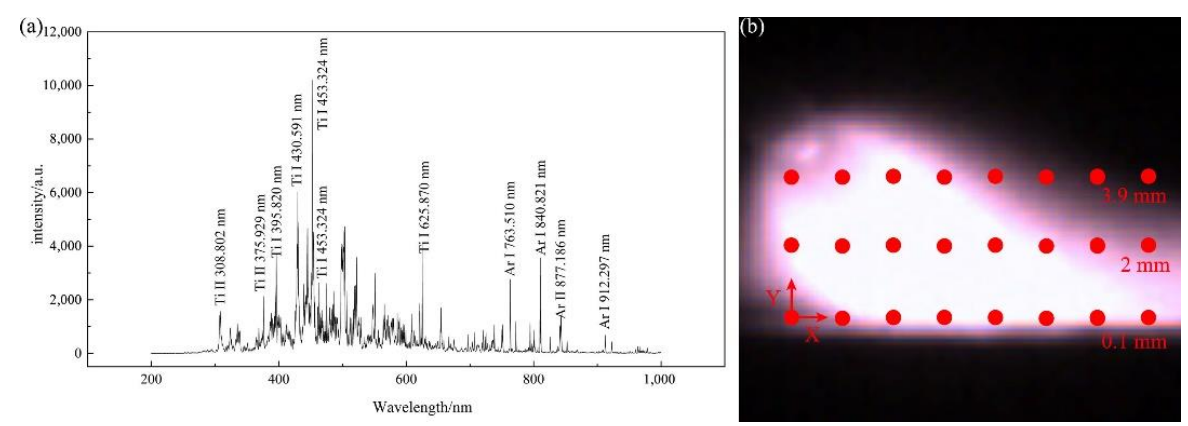

Figure 3. Spectral lines of arc plasma and the spectral acquisition positions: (a) plasma spectrum of hybrid welding; (b) spectral acquiring position on arc plasma.

The whole welding process can be divided into two alternate periods: during laser action and after laser action. In this study, the high speed camera has a high resolution time and it can distinguish each picture that is captured during laser action or after laser action. However, for the spectrograph, its resolution time is low and every measurement period includes both during the laser action period and after the laser action period. So the captured information is identified as during laser action in later descriptions for simplification. 


\subsection{Materials and Welding Conditions}

Table 1 shows the chemical compositions of the Ti-6Al-4V. The size of specimen was $10 \mathrm{~mm}$ (thickness) $\times 100 \mathrm{~mm}$ (width) $\times 200 \mathrm{~mm}$ (length), as shown in Figure 4 . The $\mathrm{V}$ groove butt joint with no gap and $1.0 \mathrm{~mm}$ root face was used in single TIG welding and laser-TIG welding. The edge was prepared according to welding conditions by a milling machine. Grease and residue on the base metal were removed with acetone, and oxidation film was removed with emery cloth and stainless steel brushes before welding. Butt joints were achieved in the TIG welding and laser-TIG hybrid welding, respectively. Welding conditions of the laser-TIG hybrid welding were shown in Table 2. After welding, cross-sections were obtained from the transverse direction of the weld and were polished, and etched in an acid solution ( $\left.2 \mathrm{vol} \% \mathrm{HF}+4 \mathrm{vol} \% \mathrm{HNO}_{3}+\mathrm{H}_{2} \mathrm{O}\right)$ for the observation of welding pool size.

Table 1. Chemical compositions of Ti-6Al-4V (wt \%).

\begin{tabular}{ccccccccc}
\hline Elements & $\mathbf{A 1}$ & $\mathbf{V}$ & $\mathbf{F e}$ & $\mathbf{C}$ & $\mathbf{N}$ & $\mathbf{O}$ & $\mathbf{T i}$ \\
\hline Wt.\% & $5.50 \sim 6.75$ & $3.50 \sim 4.50$ & 0.30 & 0.08 & 0.05 & 0.20 & residual \\
\hline & & & & & & & & \\
\end{tabular}

Figure 4. The size of specimen and groove shape.

Table 2. Welding parameters of laser-arc hybrid welding processes.

\begin{tabular}{cccc}
\hline Parameters & Value of Single TIG & \multicolumn{2}{c}{ Laser-TIG Hybrid Welding } \\
\cline { 2 - 4 } & & Value Laser & Value TIG \\
\hline Power source type & $\mathrm{DC}$ & Pulse & $\mathrm{DC}$ \\
Electrode type & $\mathrm{W}-2 \% \mathrm{ThO}_{2}$ & - & $\mathrm{W}-2 \% \mathrm{ThO}_{2}$ \\
Diameter of electrode, $(\mathrm{mm})$ & 3.2 & - & 3.2 \\
Angle of electrode $(\theta),{ }^{\circ}$ & 45 & 90 & 45 \\
Welding current $(I), \mathrm{A}$ & 260,300 & - & 200 \\
Laser pulse energy $(Q), \mathrm{J}$ & - & 20 & - \\
Laser pulse frequency $(f), \mathrm{Hz}$ & - & 20 & - \\
Dla, $(\mathrm{mm})$ & - & - & $2,3.5$ \\
Shielding gas type & Pure Ar & - & Pure Ar \\
Gas flow rate $(q), \mathrm{L} / \mathrm{min}$ & 15 & - & 4 \\
Arc length $(l), \mathrm{mm}$ & 4 & 400 & 400 \\
Welding speed $(v), \mathrm{mm} / \mathrm{min}$ & 400 & & \\
\hline
\end{tabular}

\section{Results and Discussion}

\subsection{Back Appearance and Cross Section of Weld Bead}

Figure 5 shows the back surface and cross section of a weld seam of single TIG and hybrid welding. From Figure 5a, it can be found that the back surface of the weld seam produced by single TIG welding, presents incomplete fusion. The heat input is $390 \mathrm{~J} / \mathrm{mm}$. If the welding current is increased, and other parameters remain constant, the burn through on the back of the weld penetration can be seen, as shown in Figure 5b. The heat input is about $448 \mathrm{~J} / \mathrm{mm}$. During the laser-TIG welding process, 
adjusting the Dla, welding current of TIG, laser pulse energy, a sound fusion shape in butt welding of a thick plate root layer can be realized under a group of certain condition: $Q=20 \mathrm{~J}, f=20 \mathrm{~Hz}$, $I=200 \mathrm{~A}, v=400 \mathrm{~mm} / \mathrm{min}, D l a=2 \mathrm{~mm}$, as presented in Figure $5 \mathrm{c}$. The heat input of hybrid welding is about $358 \mathrm{~J} / \mathrm{mm}$. Seen from the transverse section of hybrid welding, it is found that both sides are fusion sound. The back weld width $2 \mathrm{~mm}$ and root reinforcement $0.4 \mathrm{~mm}$ are moderate. Figure $5 \mathrm{~d}$ presents the weld appearance of the hybrid weld samples under the condition of Dla $3.5 \mathrm{~mm}$, and other conditions are same as in Figure 5c. It is found that with the Dla increase to $3.5 \mathrm{~mm}$, the back weld will present an undercut defect. This means that the addition of pulse laser can promote the heat transfer to the depth of the penetration, and Dla plays an important role in the heat distribution of the pool in the laser-TIG hybrid welding process. The sound and uniformed formation of the bottom can be realized by hybrid welding process because the laser makes appropriate heat distribution in the molten pool.

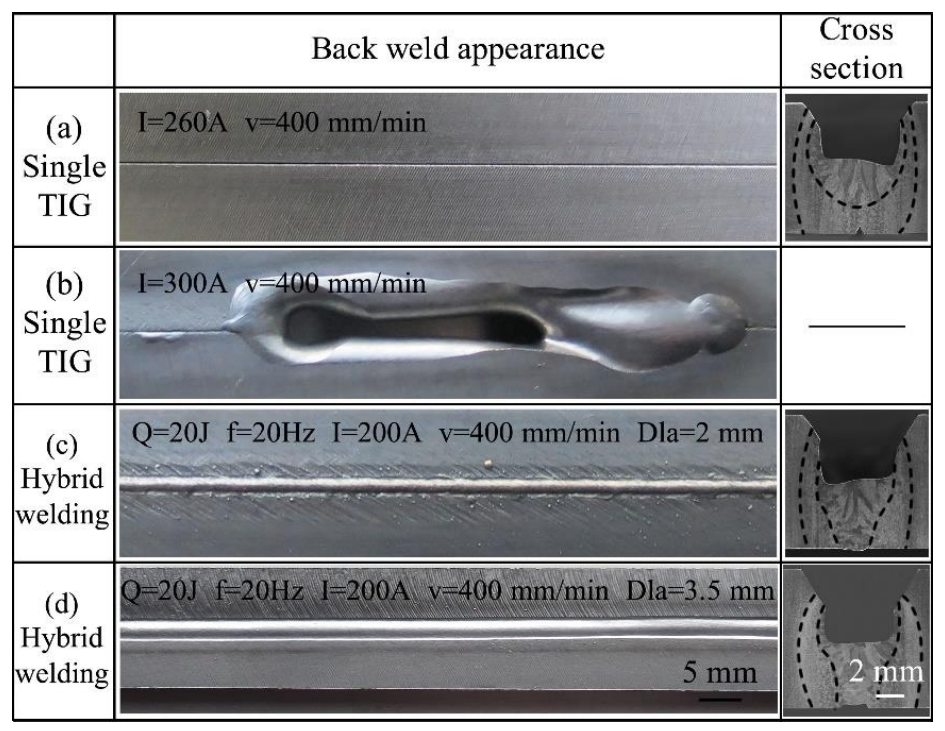

Figure 5. Back surface and cross section of weld seam with single tungsten inert gas (TIG) and hybrid welding: (a) single TIG; (b) single TIG; (c) hybrid welding; (d) hybrid welding.

After welding, the optical microstructure of the fusion zoon (FZ) and heat affected zoon (HAZ) with the parameters of Figure $5 c$ are adopted to carry out the analysis, as shown in Figure $6 a, b$ respectively. Due to the difference of the cooling rate in the FZ and HAZ, their weld microstructure presents different morphology. Because of the slower cooling in FZ, a number of bulky columnar crystals with the acicular phase $\alpha^{\prime}$ phase and small amount of the primary $\beta$ phase increased in FZ, as shown in Figure 6a. Due to the fast cooling in HAZ, the globular phase with the mixed pattern of the acicular martensite and the primary $\alpha$ phase appeared in the HAZ, as shown in Figure $6 \mathrm{~b}$.
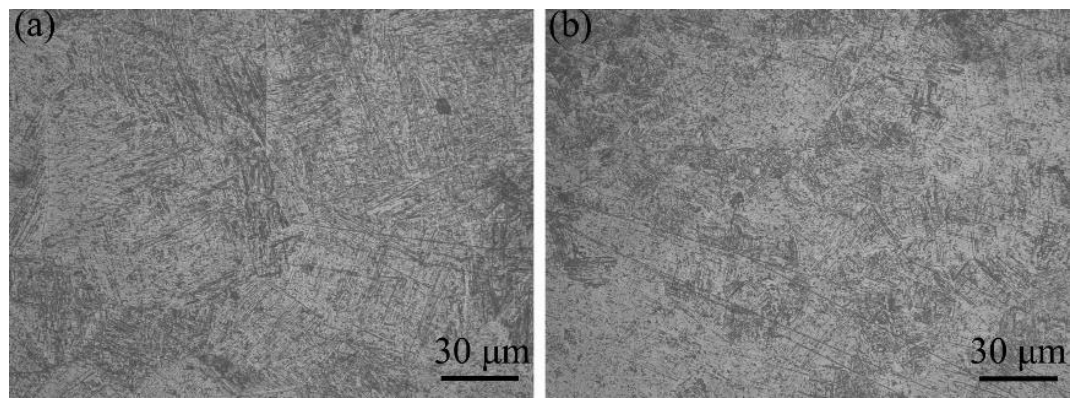

Figure 6. Optical microstructure of weld: (a) fusion zoon (FZ); (b) heat affected zoon (HAZ). 


\subsection{Arc Behaviors Observation}

In order to facilitate the observation, bead-on-plate welding experiments were carried out. To detail the comparisons of arc state, the arc behaviors from a side view were captured by a high speed camera. Figure 7 shows the arc behaviors in single TIG and hybrid welding with the Dla $2 \mathrm{~mm}$, respectively. The welding parameters are listed in Table 2. As illustrated in Figure 7, due to the DC current being employed in this experiment, in single TIG welding the arc always discharges stably along the tungsten extension. However, the arc is compressed cyclically with the pulse laser in hybrid welding. In comparison with single TIG welding, the $4 \mathrm{~mm}$ distance between the tip of the tungsten and discharge position, is reduced to $2 \mathrm{~mm}$ with laser action. This quantitative description proves that with the action of laser pulses, the arc will act at different locations of the molten pool periodically.

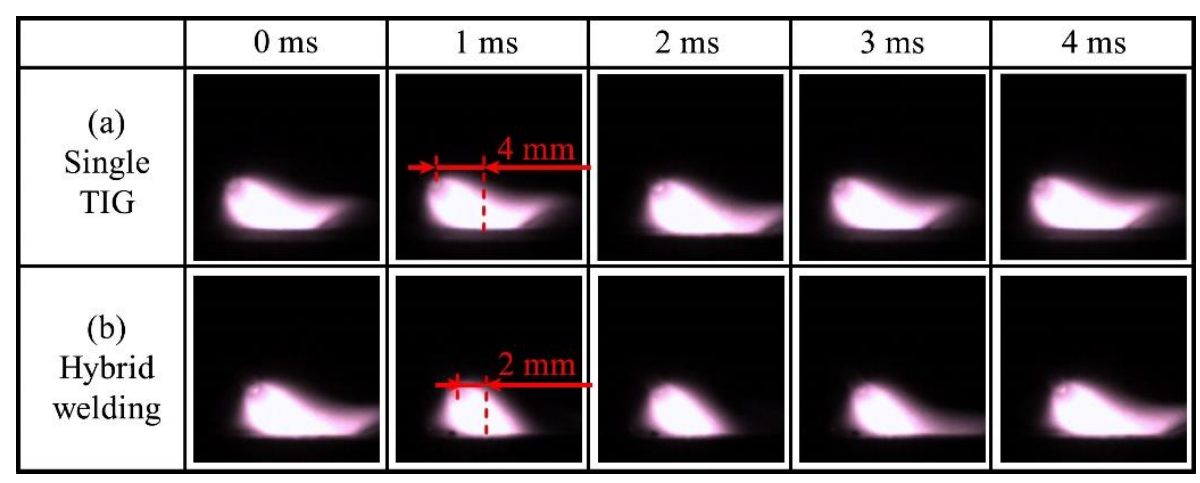

Figure 7. Arc behaviors in different welding process: (a) single TIG; (b) hybrid welding.

The electronic temperature, which is considered as a main metric of the average kinetic energy of the mico-particles in the plasma, is an important measurement to study the heat and mass transfer of plasma, and it also reflects the spatial distribution of the arc state from the other side [19]. Figure 8 shows the major difference of distribution of the electronic temperature between TIG welding and hybrid welding. The result shows that the distribution of electronic temperature presents the dispersing state in TIG welding, but the compressing state in hybrid welding. In the hybrid welding process, although the electronic temperature near the region where laser acts is decreased, the high temperature region is compressed directly above the laser keyhole. Compared with TIG welding, the axis of high temperature region in the hybrid welding process changes from a straight line to a curve. In the hybrid welding process, the plasma is located above the laser action point vertically and connects to the electrode obliquely. This phenomenon is also shown in Figure 9. The electronic temperature decreases from the tungsten electrode to the workpiece in the TIG welding process while it decreases firstly and then increases again from tungsten electrode tip to laser action spot in the hybrid welding process. The addition of the laser is the main factor which causes this change of the distribution of the electronic temperature in hybrid welding process. When the laser is added, titanium is vaporized rapidly with low ionization energy, Ti atoms are ionized and thus plasma with recoil pressure is formed. The recoil pressure causes the laser induced plasma to be distributed vertically above the laser keyhole. The titanium atoms are cumulatively ionized due to the collision with high-energy electrons. The laser keyhole will supply plenty of electrons for arc plasma, so the conducting route changes. 


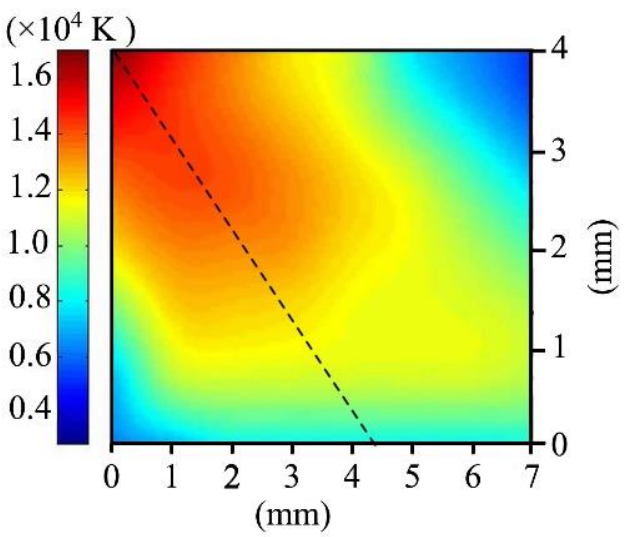

(a) TIG welding

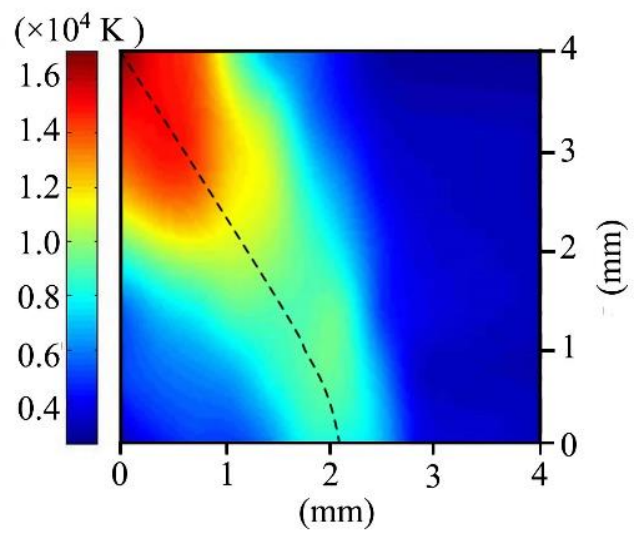

(b) Hybrid welding

Figure 8. Distribution of plasma temperature in different welding process: (a) single TIG; (b) hybrid welding.

(a)

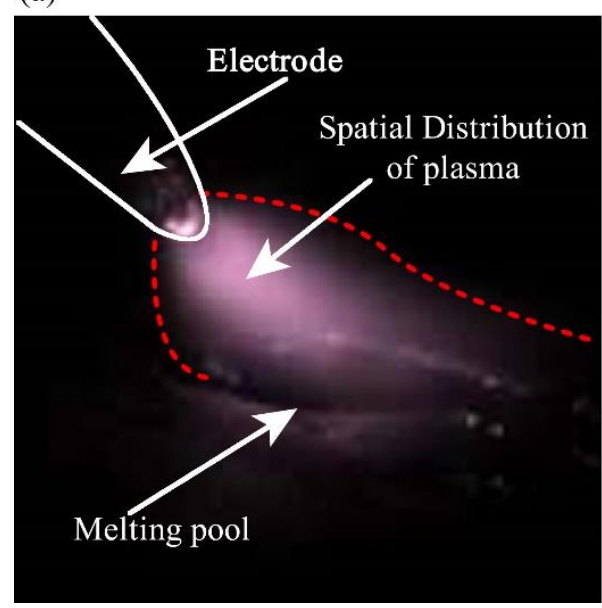

(b)

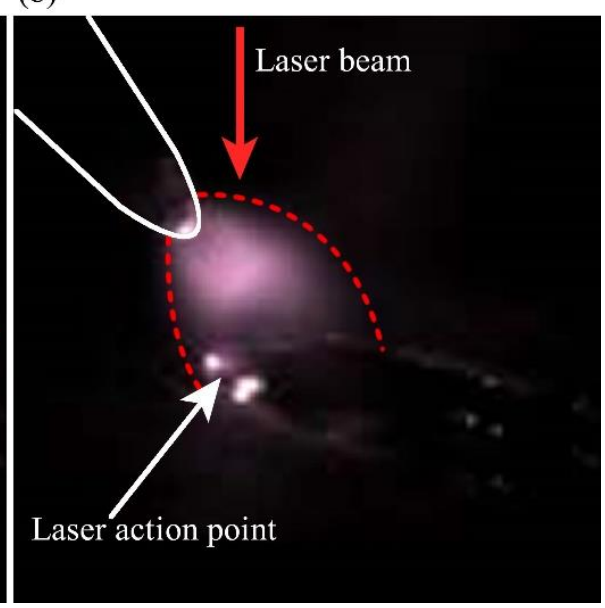

Figure 9. Melting pool behaviors in different welding process: (a) single TIG; (b) hybrid welding.

\section{Discussion}

\subsection{Arc Deflection}

The arc deflection is determined by electromagnetic force between the TIG arc and the laser induced plasma. As noted in the paper written by Chen [20], when the laser acts on a workpiece, there are two currents with the same direction between the electrode and the workpiece. A simplified model is established to calculate the deflected length. Figure 10 shows a schematic illustration of the arc attraction between the laser and arc. In this case, the TIG arc is attracted and repulsed outwards because of the electromagnetic forces.

Generally speaking, the deflected length $d$ can be expressed by the following Formula (1) [21],

$$
d=\frac{h^{2} I_{L}}{2 I_{a} D_{L M}} \cos \theta
$$

where $d$ is the deflected length for the pulsed TIG arc, $h$ is the length for the TIG arc, $I_{L}$ is the current in the keyhole, $I_{a}$ is the TIG arc current and $D_{L M}$ the arc distance. However, in this paper the arc is expected to be completely attracted to the laser keyhole, so $D_{L M}=d=D l a=2 \mathrm{~mm}$, thus the formula becomes 


$$
d=\sqrt{\frac{h^{2} I_{L}}{2 I_{a}} \cos \theta}
$$

Therefore, the required minimum keyhole current, that can provide enough energy to attract the arc root to the laser action point, is calculated to be $142 \mathrm{~A}$.

Figure 11 shows a comparison of the required keyhole current calculated for different deflected lengths at an arc current of 100, 200 and $300 \mathrm{~A}$. It can be seen that in the case of a certain arc current, with the increase of the deflected length, the required keyhole current increases. For the same deflected length, the required keyhole current increases with the increase of the arc current. Besides, as the deflected length increases, the larger the arc current is, the greater the keyhole current must be.

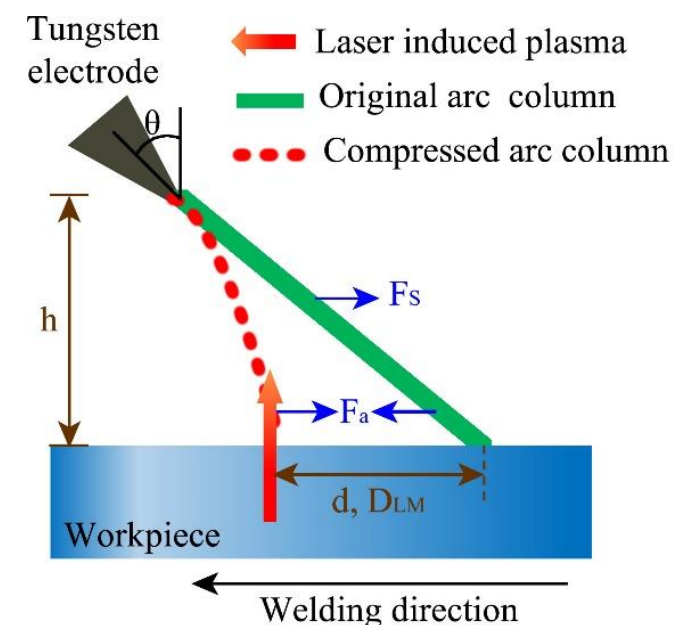

Figure 10. Schematic illustration of arc attraction between laser and arc.

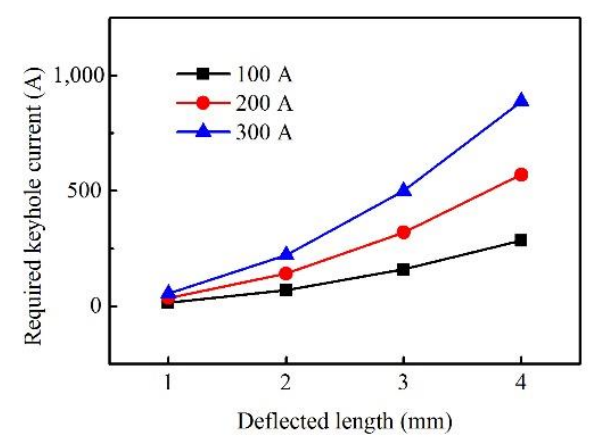

Figure 11. Relationship between required keyhole current and deflected length.

In addition, the current $I_{L}{ }^{\prime}$ in the keyhole can be given by Ohm's law [22].

$$
I_{L}^{\prime}=2 \pi E \int_{0}^{R} \sigma r d r=\pi R^{2} \sigma E
$$

and the specific electrical conductivity of the laser induced plasma in the keyhole $\sigma$ is given by

$$
\sigma=\frac{3}{4} \frac{\left(k T_{e}\right)}{\sqrt{2 \pi m_{e}} \lambda_{e} e^{2}}
$$

where $E$ is the axial component of the electric field intensity in the keyhole, $\sigma$ is the specific electrical conductivity of the laser induced plasma in the keyhole, $R$ is the radius of the current conducting 
region. $R$ is considered as the approximate radius of keyhole, when the keyhole is assumed to be a cylinder. $k$ is the Boltzmann constant, $T_{e}$ is the electronic temperature in keyhole, $m_{e}$ is the electronic mass, $\lambda_{e}$ is the free path and $e$ is the electron charge.

In this experiment, the values of $\lambda_{e}, T_{e}$ and $E$ are approximately $0.75 \mathrm{~mm}, 15,000 \mathrm{~K}$ (usually keyhole electron temperature is higher than that in arc) and $3 \mathrm{~V} / \mathrm{mm}$, respectively. Therefore, $\sigma$ can be approximately estimated to be $1.2 \times 10^{4} \mathrm{~S} / \mathrm{m}$, and the instantaneous current of keyhole $\vec{I}_{L}$ is about $10^{3} \mathrm{~A}$. It is obvious that $I_{L}{ }^{\prime} \geq I_{L}$ meaning that in this part of experiment the arc is easily attracted by the laser induced plasma produced by a pulse laser.

\subsection{Analysis of Forces on Back Molten Pool}

The shape, dimension and the volume of the molten pool have significant influence on the weld shape in the welding process, especially in root welding. In one-side welding with back formation in the root welding process, the metal is melted into the molten pool and then frozen into welds. There are several mechanisms that influence the stability of the molten pool in the welding process as sketched in Figure 12. First, in the combined effect of arc pressure, gravitational force, surface tension, adhesive force between the molten pool and front base metal or back solidification weld, the back liquid metal hangs in the space. The last two forces are the function of temperature. According to the Formula (5), only when the four forces coordinate with each other and balances can the molten pool keep stability [23].

$$
F_{\sigma}+F_{\delta}=F_{m}+F_{A} \sin \theta
$$

where $F_{\sigma}$ is the surface tension, $F_{\delta}$ is the adhesive force, $F_{m}$ is the gravity, $F_{A}$ is the arc pressure, $\theta$ is the angle of electrode.

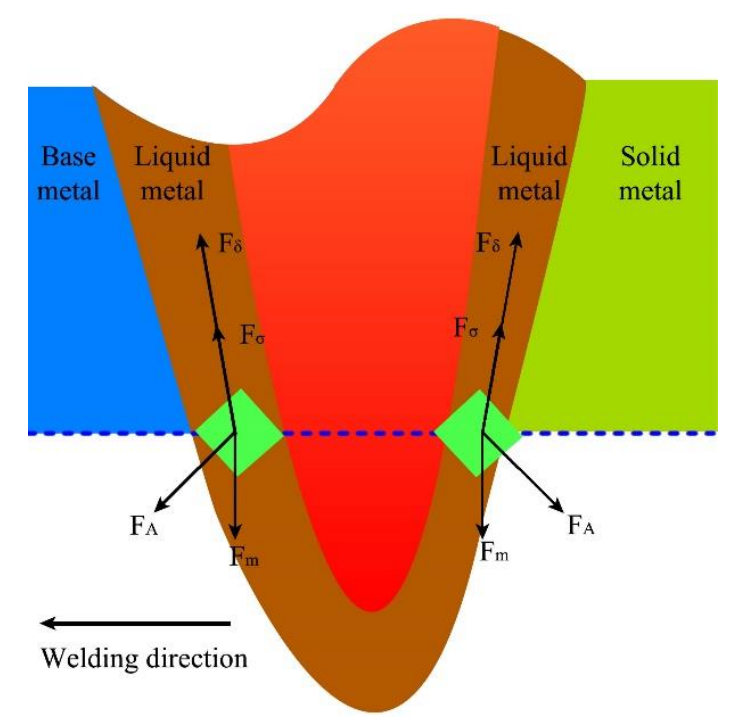

Figure 12. Schematic diagram of the forces acts on back molten pool.

However, according to present research, surface tension and adhesive force are a function of temperature. Therefore, the higher the temperature is, the lower the surface tension and adhesive force. Uneven temperature distribution will inevitably lead to uneven surface tension and adhesive force distribution. The gravity determined by the dimension of the molten pool is also affected by temperature. The higher the temperature, the larger the dimension of the molten pool will get. The temperature of the molten pool is proportional to gravity and inversely proportional to the surface tension and adhesive force. Meanwhile, due to the top and back of the molten pool always being interconnected in the welding process, the arc passes through the molten pool and acts on the back molten pool directly. So it is important to control the shape of the back molten pool by adjusting the 
temperature distribution over the top of the molten pool. According to manual arc welding for one side welding with back formation, the arc distribution on the molten pool front rim plays a decisive role in weld bead formation on the back side [24-27].

\subsection{The Effect of Pulsed Laser in Welding Process}

In this research, during pulsed laser-arc welding, the state of the melting pool is closely related to the periodical behavior of the liquid metal. Figure 13 shows the relative location of the arc and the molten pool in different welding processes. As illustrated in Figure 13a, during single TIG welding, because of the arc stiffness caused by the high-power jet from the tungsten electrode, the arc always completely covers the molten pool and arc force acts on the surface of the molten pool along the extension of the tungsten electrode. Due to lower energy density of single TIG welding, the incomplete penetration may be caused with higher linear energy. However, a small increase in linear energy requires an increase in arc current. According to Formula (6), the arc pressure is proportional to the square of the currents, so the increase of current will result in the increase of arc pressure, arc stiffness and size of the molten pool, ultimately causing the weld to be burnt through [28,29].

$$
F=\frac{\mu}{4 \pi} \times \frac{I_{a}^{2}}{\pi R^{2}}\left(R^{2}-r^{2}\right)
$$

where $I_{a}$ is the arc current, $\mu$ is the arc magnetic permittivity, $F$ is the arc static pressure, $R$ is the radius of the arc, $r$ is the distance from arbitrary points to the axial of arc.

(a)

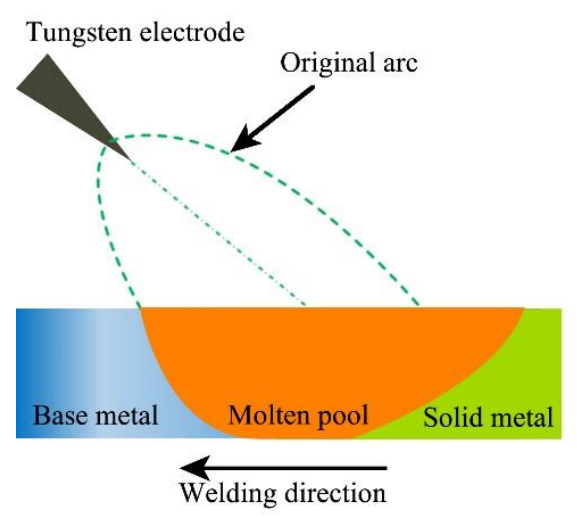

(b)

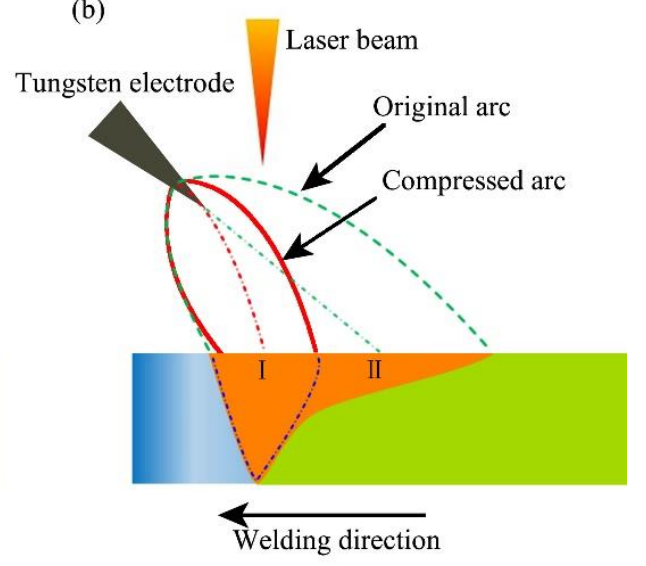

Figure 13. Schematic diagram of molten pool in different welding process: (a) single TIG; (b) hybrid welding.

A balance state of four-balance forces (surface tension, arc force, gravity and adhesive force) is difficult to achieve with liquid titanium alloys with lower and changeable surface tension at the melting point. It can be found that TIG welding with single type and poor tolerance is difficult to control in the welding process.

Figure $13 \mathrm{~b}$ presents the schematic diagram of the arc and molten pool in hybrid welding, in comparison with Figure 13a, it can be seen that the molten pool along the welding direction can be divided into front molten pool area I named the hybrid heat source action area and rear molten pool area II named the arc action area, and this differs from TIG welding in which a single molten pool is formed. This is mainly because the original arc is attracted and enhanced by laser induced plasma during laser action, and the arc column is compressed, deflected and attracted to the laser action point over the top of the molten pool. Meanwhile, in the case of high energy density gradient, arc energy is transferred along the direction of penetration. After laser action, the arc restores to its original state with low energy density and acts on the molten pool. Under the action of the pulsed laser, the 
enhanced arc alternates as the original arc acts on the pool area I and II, respectively. When the laser acts on area I, metal in area I is melted forming a molten pool. However, without arc action, the bottom of the molten pool in area II would solidify into a weld seam due to a very large amount of heat being taken away from the molten pool by shielding gas. After laser action, the molten pool is completely covered by a low energy density arc and the arc heat is not enough to fully melt the bottom of the weld seam into molten pool, so the bottom of the molten pool is still solid. In this case, the top of the liquid metal will be held by the bottom weld seam. Meanwhile, the length of the molten pool is shortened along the welding direction. In this situation, the four forces make it easy to achieve balance and a stable molten pool is obtained.

\section{Conclusions}

According to the results and analysis, the following conclusions can be achieved.

The addition of a pulse laser can promote the heat transfer downward along the penetration, and compared with single TIG welding, a sound and uniformed formation of the bottom can be realized with lower heat input in the root hybrid welding process.

In root hybrid welding, the attraction force of the laser induced plasma on the TIG arc plays an important role in the arc distribution over the top molten pool surface, and this influences the weld bead formation on the back side. Under the condition that the arc alternates between the enhanced state and the original state, the balance of force and heat is reached, and the stable molten is achieved.

Acknowledgments: The authors gratefully acknowledge the sponsorship from Natural Science Foundation of China (No. 11375038), Science Fund for Creative Research Groups of NSFC (No. 51621064).

Author Contributions: Jipeng Shi, Liming Liu and Yanbin Zhou conceived, designed and performed the experiments. Jipeng Shi and Liming Liu analyzed the data. All authors contributed to the preparation of the manuscript.

Conflicts of Interest: The authors declare no conflict of interest.

\section{References}

1. Fu, J.; Gong, L.; Zhang, Y.; Wu, Q.; Shi, X.; Chang, J.; Lu, J. Microstructure and Mechanical Properties of Ti-6Al-4V Fabricated by Vertical Wire Feeding with Axisymmetric Multi-Laser Source. Appl. Sci. 2017, 7, 227. [CrossRef]

2. Karpagaraj, A.; Siva, S.N.; Sankaranarayanasamy, K. Some studies on mechanical properties and microstructural characterization of automated TIG welding of thin commercially pure titanium sheets. Mater. Sci. Eng. A 2015, 640, 180-189. [CrossRef]

3. Cui, L.; He, D.Y.; Guo, F.; Li, X.Y.; Jiang, J.M. Effect of fiber laser-MIG hybrid process parameters on weld bead shape and tensile properties of commercially pure titanium. Mater. Manuf. Process. 2010, 25, 1309-1316.

4. Saresh, N.; Pillai, M.G.; Mathew, J. Investigations into the effects of electron beam welding on thick Ti-6Al-4V titanium alloy. J. Mater. Process. Technol. 2007, 192-193, 83-88. [CrossRef]

5. Li, X.; Wu, C.; Li, W. Study on progress of welding science and technology in China. J. Mech. Eng. 2012, 6, 19-31. [CrossRef]

6. Yamane, S.; Yamamoto, H.; Ishihara, T.; Kubota, T.; Eguchi, K.; Oshima, K. Adaptive control of back bead in V groove welding without backing plate. Sci. Technol. Weld. Join. 2004, 9, 138-148. [CrossRef]

7. Schneider, A.; Gumenyuk, A.; Lammers, M.; Malletschek, A.; Rethmeier, M. Laser Beam Welding of Thick Titanium Sheets in the Field of Marine Technology. Phys. Procedia 2014, 56, 582-590. [CrossRef]

8. Chen, Y.; Zhang, K.; Hu, X.; Lei, Z.; Ni, L. Study on laser welding of a Ti-22Al-25Nb alloy: Microstructural evolution and high temperature brittle behavior. J. Alloys Compd. 2016, 681, 175-185. [CrossRef]

9. Campanelli, S.L.; Gasalino, G.; Mortello, M.; Angelastro, A.; Ludovico, A.D. Microstructural charateristics and mechanical properties of Ti6Al4V alloy fiber laser welds. Procedia CIRP 2015, 33, 428-433. [CrossRef]

10. Chen, M.; Xu, J.; Xin, L.; Zhao, Z.; Wu, F.; Ma, S.; Zhang, Y. Effect of keyhole characteristics on porosity formation during pulsed laser-GTA hybrid welding of AZ31B magnesium alloy. Opt. Lasers Eng. 2017, 93, 139-145. [CrossRef] 
11. Brandizzi, M.; Satriano, A.A.; Sorgente, D.; Tricarico, L. Laser-arc hybrid welding of Ti6Al4V titanium alloy: Mechanical characterization of joints and gap tolerance. Weld. Int. 2013, 27, 113-120. [CrossRef]

12. Liu, L.; Li, C.; Shi, J. Analysis of energy utilisation efficiency in laser-GTA hybrid welding process. Sci. Technol. Weld. Join. 2014, 19, 541-546. [CrossRef]

13. Lee, C.M.; Woo, W.S.; Baek, J.T.; Kim, E.J. Laser and arc manufacturing processes: A review. Int. J. Precis. Eng. Manuf. 2016, 17, 973-985. [CrossRef]

14. Turichin, G.; Tsibulsky, I.; Somonov, V.; Kuznetsov, M.; Akhmetov, A. Laser-TIG Welding of Titanium Alloys. IOP Conf. Ser. Mater. Sci. Eng. 2016, 142, 012009. [CrossRef]

15. Zhang, K.Z.; Lei, Z.L.; Chen, Y.B.; Liu, M.; Liu, Y. Microstructure characteristics and mechanical properties of laser-TIG hybrid welded dissimilar joints of Ti-22Al-27Nb and TA15. Opt. Laser Technol. 2015, 73, 139-145. [CrossRef]

16. Liu, L.M.; Hao, X.F.; Du, X. Microstructure characteristics and mechanical properties of Laser-TIG hybrid welding joint of TA15 titanium alloy. Mater. Res. Innov. 2008, 12, 114-118. [CrossRef]

17. Cao, Y.M. Study on Laser-TIG Arc Hybrid Welding Process of Medium Titanium Aloy Plate. Master's Thesis, Dalian University of Technology, Dalian, China, June 2011.

18. Chen, M.H.; Li, C.B.; Liu, L.M. Coupling discharge between keyhole plasma and arc plasma in laser-arc welding of Mg alloy. IEEE Trans. Plasma Sci. 2014, 42, 1400-1406. [CrossRef]

19. Chen, M.; Xu, J.; Xin, L.; Zhao, Z.; Wu, F. Comparative study on interactions between laser and arc plasma during laser-GTA welding and laser-GMA welding. Opt. Lasers Eng. 2016, 85, 1-8. [CrossRef]

20. Gu, X.; Li, H.; Yang, L.; Gao, Y. Coupling mechanism of laser and arcs of laser-twin-arc hybrid welding and its effect on welding process. Opt. Laser Technol. 2013, 48, 246-253. [CrossRef]

21. Ueyama, T.; Ohnawa, T.; Tanaka, M.; Nakata, K. Occurrence of arc interaction in tandem pulsed gas metal arc welding. Sci. Technol. Weld. Join. 2007, 12, 523-529. [CrossRef]

22. Chen, M.H.; Liu, L.M. Study on Attraction of Laser to Arc Plasma in Laser-TIG Hybrid Welding on Magnesium Alloy. IEEE Trans. Plasma Sci. 2011, 39, 1104-1109. [CrossRef]

23. Lei, Y.P.; Murakawa, H.; Shi, Y.W.; Li, X.Y. Numerical analysis of the competitive influence of Marangoni flow and evaporation on heat surface temperature and molten pool shape in laser surface remelting. Comput. Mater. Sci. 2001, 21, 276-290. [CrossRef]

24. Wang, J.; Wu, D.; Liao, P.; Tian, C.Y.; Li, M.Q.; Feng, J.C. Metal transfer and arc behaviour of novel consumable and non-consumable electrode indirect arc droplet welding. Sci. Technol. Weld. Join. 2013, 18, 261-270. [CrossRef]

25. Gao, H.; Wu, L.; Dong, H. Numerical Simulation of Electromagnetic Force in Double-Sided Arc Welding Process. J. Mater. Sci. Technol. 2003, 19, 223-224.

26. Miao, Y.; Xu, X.; Wu, B.; Li, X.; Han, D. Effects of bypass current on the stability of weld pool during double sided arc welding. J. Mater. Process. Technol. 2014, 214, 1590-1596. [CrossRef]

27. Lu, Y.; Chen, S.; Shi, Y.; Li, X.; Chen, J.; Kvidahl, L.; Zhang, Y.M. Double-electrode arc welding process: Principle, variants, control and developments. J. Manuf. Process. 2014, 16, 93-108. [CrossRef]

28. Li, T.Q.; Wu, C.S.; Chen, J. Transient variation of arc heat flux and pressure distribution on keyhole wall in PAW. Weld. World. 2016, 60, 363-371. [CrossRef]

29. Chen, S.; Yan, Z.; Jiang, F.; Lu, Z. The pressure distribution of hollow cathode centered negative pressure arc. J. Manuf. Process. 2016, 23, 21-28. [CrossRef]

(C) 2017 by the authors. Licensee MDPI, Basel, Switzerland. This article is an open access article distributed under the terms and conditions of the Creative Commons Attribution (CC BY) license (http://creativecommons.org/licenses/by/4.0/). 